\title{
The Leaf Extract of Coccinia grandis (L.) Voigt Accelerated In Vitro Wound Healing by Reducing Oxidative Stress Injury
}

\author{
Poommaree Namchaiw $\mathbb{D}^{1,2}$ Yamaratee Jaisin, ${ }^{3}$ Cholticha Niwaspragrit, ${ }^{4}$ \\ Kittiya Malaniyom, ${ }^{3}$ Anyamanee Auvuchanon, ${ }^{5}$ and Piyanee Ratanachamnong ${ }^{6}{ }^{6}$ \\ ${ }^{1}$ Biological Engineering Program, Faculty of Engineering, King Mongkut's University of Technology Thonburi, Bangkok, Thailand \\ ${ }^{2}$ Neuroscience Center for Research and Innovation, Learning Institute, King Mongkut's University of Technology Thonburi, \\ Bangkok, Thailand \\ ${ }^{3}$ Department of Pharmacology, Faculty of Medicine, Srinakharinwirot University, Bangkok, Thailand \\ ${ }^{4}$ Expert Center of Innovative Agriculture, Thailand Institute of Scientific and Technological Research (TISTR), \\ Pathum Thani, Thailand \\ ${ }^{5}$ Department of Horticulture, Faculty of Agriculture at Kamphaeng Saen, Kasetsart University, Nakhon Pathom, Thailand \\ ${ }^{6}$ Department of Pharmacology, Faculty of Science, Mahidol University, Bangkok, Thailand
}

Correspondence should be addressed to Piyanee Ratanachamnong; piyanee.rat@mahidol.ac.th

Received 21 July 2020; Revised 10 December 2020; Accepted 18 December 2020; Published 6 January 2021

Academic Editor: Ange Mouithys Mickalad

Copyright ( 2021 Poommaree Namchaiw et al. This is an open access article distributed under the Creative Commons Attribution License, which permits unrestricted use, distribution, and reproduction in any medium, provided the original work is properly cited.

\begin{abstract}
The impairment in the regulation of the physiological process in the inflammatory phase of wound healing results in oxidative stress damage, which increases the severity and extends the healing time. In this study, we aimed to evaluate the radical scavenging properties of Coccinia leaf extract and its ability to ameliorate a migration process in vitro. Coccinia is a medicinal plant that was used in ancient times for relieving insect bite itching and swelling. However, the role of Coccinia leaf extract as an antioxidant related to the process of wound healing has never been studied. In this study, we demonstrated that the leaf extract possessed antioxidant properties that acted as a proton donor to neutralize reactive oxygen species with the $\mathrm{IC}_{50}$ value of $4.85 \mathrm{mg} / \mathrm{mL}$ of the extract. It could chelate iron with the $\mathrm{IC}_{50}$ value of $21.39 \mathrm{mg} / \mathrm{mL}$ of the extract. The leaf extract protected the human fibroblasts and keratinocytes from hydrogen peroxide-induced oxidative stress by increasing cell survival rate by more than $20 \%$ in all test doses. The protective property was dose-dependently correlated with the decrease in reactive oxygen species formation. In addition, the leaf extract enhanced the cell migration rate of fibroblasts and keratinocytes up to $23 \%$ compared with vehicle control. The results suggested that Coccinia leaf extract may be a potential herb for increasing the wound healing process with its antioxidant capacity and can be used as an herbal ingredient for the utilization of skincare products.
\end{abstract}

\section{Introduction}

The skin is the largest organ in the body. It is the first barrier to protect the internal organs from external penetration. The injury that breaks the skin that is so-called "wound" can be an acute or chronic injury, depending on the time course of the wound healing process. The physiological pathway of wound healing is characterized by the cascade of associated events including hemostasis, inflammation, proliferation, and remodeling [1]. These phases are overlapping, continuous, and indistinguishable. Following the hemostatic phase to stop the outflow bleeding, platelets, the key players, release several chemotactic factors to induce the migration of leukocytes to the site of injury $[1,2]$. The inflammation phase continues as leukocytes arrived at the lesion, encountered the invading pathogen, and scavenged cellular debris [2]. During this phase, the inflammatory cells secrete a number of cytokines and growth factors that lead to fibroblast and keratinocyte migration and initiate the next stages of wound healing: proliferation phase and remodeling phase [1-3]. As the inflammatory process continues, multiple cells are attracted to the site of injury and initiate the release of reactive oxygen 
species (ROS) and protease to get rid of the pathogens. Oxidants such as superoxide anions, hydroxyl radicals, and hydrogen peroxides are secreted by leukocytes, endothelial cells, and vascular cells [4]. The low concentration of oxidants acts as secondary messengers that modulate several downstream signaling pathways including inflammation and wound repairing process $[4,5]$. Although the secretion of oxidants has a protective role, the dysregulation of an inflammatory response such as overproduction of oxidants is cytotoxic and may contribute to a chronic wound [4]. The prolonged inflammation phase results in a chronic wound, in which the patient encounters pain and may develop an infected wound.

Keratinocytes and fibroblasts are the principal cells that reside in the epidermis and dermis, respectively [6]. Keratinocytes provide the barrier that prevents water loss and protects the dermis from penetration, while fibroblasts produce an extracellular matrix to provide the structural supportive network for surrounding cells [3]. Upon skin injury, both of them are recruited to the lesion site then undergo the morphological and functional changes to drive the granulation tissue formation, which ultimately regenerates the damaged tissue $[6,7]$. Previous studies revealed that the function of keratinocytes and fibroblasts can be impaired by excessive oxidative stress during the prolonged inflammation phase, which results in an unhealed wound $[8,9]$. The cost of wound management is rising as it progresses toward being a chronic wound. Thus, several attempts are aimed at limiting the inflammation before it develops toward a chronic, nonhealing wound.

The Coccinia grandis (L.) Voigt, commonly known as ivy gourd, is a vegetable grown in subtropical and tropical areas of South East Asia, South Asia, and Africa [10]. It is a climbing and ground-creeping plant that spreads rapidly, requires low maintenance, and is highly naturalized. Its fruits and leaves are edible either fresh or cooked and are used in cooking and as a household remedy from time to time [11-14]. In South East Asia, ivy gourd leaves are used as antibruises and anti-itching from insect bites by applying the lesion with crushed fresh leaves [15]. Previous studies showed that ivy gourd leaf extract is a good source of proteins, minerals, vitamins, and other phytochemicals (e.g., polyphenol, flavonoid, saponin, and sterol contents) $[15,16]$. Thus, it was added to meals for their medicinal effects such as antioxidant, antiulcer, anti-inflammatory, antidiabetic, and analgesic potential $[13,14,17-20]$. In addition, the potential effect on wound healing was recently observed in animal models [21, 22]. However, the mechanisms of action related to wound healing have not been determined. In this study, we demonstrated the antioxidant properties of Coccinia leaf extract which reduced oxidative stress injury in human fibroblast and keratinocytes and its potential effect on human fibroblast and keratinocyte cell migration.

\section{Materials and Methods}

2.1. Chemicals and Equipment. Methanol $\left(\mathrm{CH}_{3} \mathrm{OH}\right)$ was purchased from RCI Labscan, Thailand. Gallic acid monohydrate $\left(\mathrm{C}_{7} \mathrm{H}_{6} \mathrm{O}_{5} \cdot \mathrm{H}_{2} \mathrm{O}\right)$ and sodium carbonate anhydrous
$\left(\mathrm{Na}_{2} \mathrm{CO}_{3}\right)$ were purchased from Riedel-de Haën, Germany. Folin-Ciocalteu's phenol reagent and ethanol $\left(\mathrm{C}_{2} \mathrm{H}_{5} \mathrm{OH}\right)$ were purchased from Merck, Germany. Thiazolyl Blue Tetrazolium Bromide (MTT), allantoin, $2^{\prime}, 7^{\prime}$-dichlorofluorescin diacetate, quercetin $\left(\mathrm{C}_{15} \mathrm{H}_{10} \mathrm{O}_{7}\right)$, aluminum chloride $\left(\mathrm{AlCl}_{3}\right)$, potassium acetate $\left(\mathrm{CH}_{3} \mathrm{CO}_{2} \mathrm{~K}\right)$, ferrous sulfate heptahydrate $\left(\mathrm{FeSO}_{4} \cdot 7 \mathrm{H}_{2} \mathrm{O}\right)$, and 3-(2-pyridyl)-3,0-diphenyl-1,2,4-triazine-4-4' ${ }^{\prime}$-disulfonic acid sodium salt $\left(\mathrm{C}_{20} \mathrm{H}_{13} \mathrm{~N}_{4} \mathrm{NaO}_{6} \mathrm{~S}_{2}\right)$ were purchased from Sigma Chemical Company, USA. Dulbecco's modified Eagle medium (DMEM), heat-inactivated FBS, Non-Essential Amino Acids Solution (100x), and $0.25 \%$ trypsin-EDTA were purchased from Gibco, USA. Hydrogen peroxide and non-essential amino acid were purchased from Merck, USA. The scratch wound healing images were taken under an inverted microscope (Olympus, Japan), and the DCFH-DA assay was taken under a confocal fluorescent microscope (Olympus, Japan). The absorbance and fluorescence were evaluated with a microplate reader (BioTek Instruments, USA).

2.2. Plant Material and Extraction. Ivy gourd leaves were collected from Pathum Thani agricultural plot, Thailand. The voucher specimen has been deposited at the Herbarium of Forest Botany Division, Department of National Parks, Wildlife and Plant Conservation, Thailand. The dried leaves $(50 \mathrm{~g})$ were extracted with $95 \%$ methanol at room temperature. The solvent was renewed every 48 hours three times. The extract was filtered and concentrated under the reduced pressure rotary evaporator. The dried sample was kept in desiccators until performing further experiments. The methanol leaf extract sample used in cell line treatment was diluted with DMSO (final concentration of 200, 100, and $50 \mu \mathrm{g} / \mathrm{mL}$ in $0.1 \%$ DMSO). Vehicle control was $0.1 \%$ DMSO.

\subsection{Chemical Investigation}

2.3.1. Total Phenolic Contents. The total phenolic content of the leaf extract was determined by the colorimetric method as described by Slinkard and Singleton [23]. In brief, $30 \mu \mathrm{L}$ of methanol leaf extract or the reference standard gallic acid was dissolved in $790 \mu \mathrm{L}$ deionized water. The mixture was then mixed with $50 \mu \mathrm{L}$ Folin-Ciocalteu's phenol reagent and incubated at room temperature for 5 minutes before adding $150 \mu \mathrm{L}$ saturated $\mathrm{Na}_{2} \mathrm{CO}_{3}$ and further incubated at room temperature for 50 minutes. The total polyphenol contents were measured at a wavelength of $750 \mathrm{~nm}$ and expressed as milligram gallic acid equivalents (GAE) per gram of extract.

2.3.2. Total Flavonoid Contents. The total flavonoid content was determined by the aluminum chloride colorimetric method as described by Chang et al. [24]. In brief, $100 \mu \mathrm{L}$ extract or reference standard quercetin solution was dissolved in $560 \mu \mathrm{L}$ deionized water, $20 \mu \mathrm{L}$ of $1 \mathrm{M}$ potassium acetate, and $300 \mu \mathrm{L} 95 \%$ ethanol. The mixture was mixed with $100 \mu \mathrm{L}$ of $10 \%$ aluminum chloride then incubated at room temperature for 30 minutes. The total flavonoid content of the leaf extract was measured at a wavelength of 
$415 \mathrm{~nm}$. The amount of total flavonoid of the methanol leaf extract was expressed as quercetin equivalents (QE).

\subsection{Evaluation of Antioxidant Activity}

2.4.1. DPPH Free Radical Scavenging Assay. The free radical scavenging activity was measured by DPPH scavenging assay. DPPH is a stable free radical and a strong purple color which can be measured by a spectrophotometer [25]. In the presence of antioxidant compounds, the DPPH became discolored by receiving an electron or hydrogen atom. To identify the antioxidant property of the leaf extract, the decrease of DPPH absorbance was determined. Briefly, $20 \mu \mathrm{L}$ of the extract was mixed with $180 \mu \mathrm{L}$ DPPH solution in a 96-well plate and the absorbance was measured at $515 \mathrm{~nm}$. Trolox, a vitamin $\mathrm{E}$ derivative, was used as a reference. The antioxidant activity was calculated as the percentage of scavenging activity.

2.4.2. Ferrous Ion Chelating Activity. $50 \mu \mathrm{L}$ of $5 \mathrm{mM}$ ferrozine was mixed with $25 \mu \mathrm{L}$ of $2 \mathrm{mM} \mathrm{FeSO}_{4}$. Ferrozine is a chromophoric complexing agent that selectively binds with ferrous ions to form a stable water-soluble compound, which has an absorbance at $562 \mathrm{~nm}$. To determine the chelating activity, the leaf extract was added into the reaction and the decrease of absorbance was evaluated. EDTA, a versatile chelating agent, was used as a reference.

2.5. Cell Culture. Human fibroblast cell line $\mathrm{HFb}$ (ATCC ${ }^{\circledR}$ CRL-2429 ${ }^{\mathrm{TM}}$, USA) was purchased from ATCC, USA. Human keratinocyte cell line $\mathrm{HaCaT}$ was purchased from Cell Lines Service, Germany. HFb was grown in DMEM with high-glucose complete medium and supplemented with $10 \%$ heat-inactivated FBS. HaCaT was grown in DMEM with high-glucose complete medium and supplemented with $10 \%$ heat-inactivated FBS and $5 \mathrm{~mL}$ of Non-Essential Amino Acids Solution. The cultures were rinsed with PBS solution before dissociated with $0.125 \%$ trypsin-EDTA. The cell suspensions were plated and cultured in a plastic $75 \mathrm{~cm}^{2}$ flask at $37^{\circ} \mathrm{C}, 5 \% \mathrm{CO}_{2}$. After seeding, the cells were allowed for growth for 24 hours before performing further experiments.

2.6. Cell Viability. To investigate the nontoxic concentrations of the methanol extract and a toxic concentration of $\mathrm{H}_{2} \mathrm{O}_{2}$, cells were seeded on 96-well culture plates with a density of $25 \times 10^{3}$ cells/well and incubated at $37^{\circ} \mathrm{C}, 5 \% \mathrm{CO}_{2}$ overnight. The various concentrations of the extract and hydrogen peroxide were treated on cell culture for 24 hours, and cell viability was determined using the MTT assay; the absorbance was measured at $540 \mathrm{~nm}$ by a microplate reader. The protective effect of the leaf extract on hydrogen peroxide-induced cytotoxicity was performed by treated cell culture with the extract for 2 hours before treatment with hydrogen peroxide. The percentage of cell viability was calculated relative to vehicle control.

2.7. Evaluation of Intracellular Reactive Oxygen Species by DCFH-DA Assay. The experiment was performed according to the manufacturer's recommendation (Invitrogen, CA, USA). In brief, this assay is based on the oxidation of the nonfluorescent probe $2^{\prime}, 7^{\prime}$-dichlorofluorescin diacetate (DCFH-DA) by intracellular ROS to yield the highly fluorescent $2^{\prime}, 7^{\prime}$-dichlorofluorescein (DCF). Keratinocytes $(\mathrm{HaCaT})$ and fibroblasts $(\mathrm{HFb})$ cells were seeded on a 96 well plate at a density of $25 \times 10^{3}$ cells/well in $10 \%$ FBS in DMEM medium and cultured at $37^{\circ} \mathrm{C}, 5 \% \mathrm{CO}_{2}$ overnight. After that, cells were treated with the leaf extract for 2 hours before hydrogen peroxide was added and further incubated at $37^{\circ} \mathrm{C}, 5 \% \mathrm{CO}_{2}$ overnight. The medium was then removed and stained with DCFH-DA for 1 hour. The staining medium was then removed and followed by one time washing with 1x PBS buffer, and the fluorescence intensity was immediately analyzed at excitation and emission of 485 and $528 \mathrm{~nm}$. The fluorescence intensity reflected the intracellular ROS formation. The data were represented as fold changes relative to vehicle control, and the generation of ROS was analyzed in each cell separately.

2.8. Evaluation of the Effect of Coccinia Leaf Extract on Scratch Wound Healing. Human keratinocyte and fibroblast were seeded on a 24 -well plate with a density of $2 \times 10^{5}$ cells/well and cultured at $37^{\circ} \mathrm{C}, 5 \% \mathrm{CO}_{2}$ overnight. The adherent cell layer was scratched with a sterile tip and treated with various concentrations of the leaf extract. The images of the scratched area were captured at 15 hours after scratching and then analyzed with the ImageJ software (National Institutes of Health, US). The percentage of cell migration to cover the scratched area was calculated and presented as a relative number to time zero.

2.9. Statistical Analysis. The chemical analysis of total phenolic and flavonoid contents was measured 10 replicates of multiple concentrations. The average was plotted to make a standard curve and the number of chemical equivalents to GAE and QE was calculated, respectively. Other experiments, one-way ANOVA with Dunnett's post hoc analysis of 6 replicates, were used to perform the statistical analysis.

\section{Results}

3.1. Polyphenolic and Flavonoid Contents. Polyphenolic and flavonoid compounds are the chemical structure containing multiple hydroxyl substituents on an aromatic ring. Due to their structure, polyphenol compounds are good electron and proton donors. They are capable to scavenge free radicals and reduce oxidative stress by transferring $\mathrm{H}$-atom from their hydroxyl group(s) to free radicals [26]. Previous studies revealed that the possession of multiple hydroxyl groups that attached to the aromatic ring manipulated the antioxidant activity as a free radical scavenging and metal ion chelating site; the more they have hydroxyl groups the more they are antioxidant $[26,27]$. In this study, we showed that Coccinia leaf extract contained a polyphenolic content of $104.88 \pm$ $0.8 \mathrm{mg}$ GAE equivalent per gram of extract and flavonoid content of $35.35 \pm 1.82 \mathrm{mg} \mathrm{QE}$ equivalent per gram of extract. Therefore, the presence of polyphenolic and flavonoid contents in the leaf extract may contribute to its antioxidant activity. 


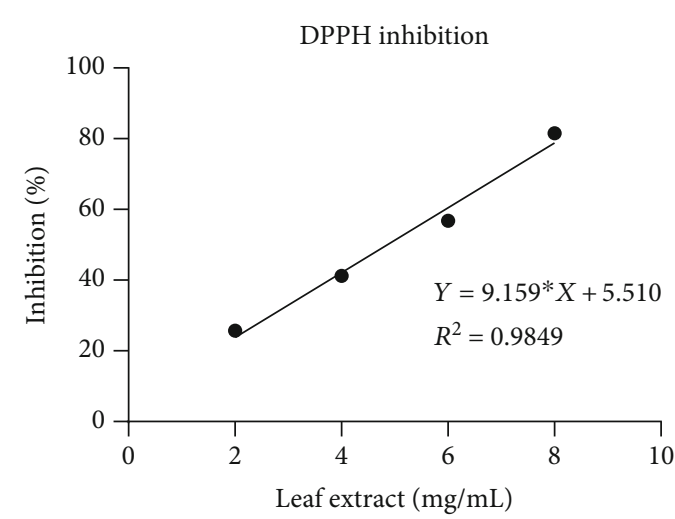

(a)

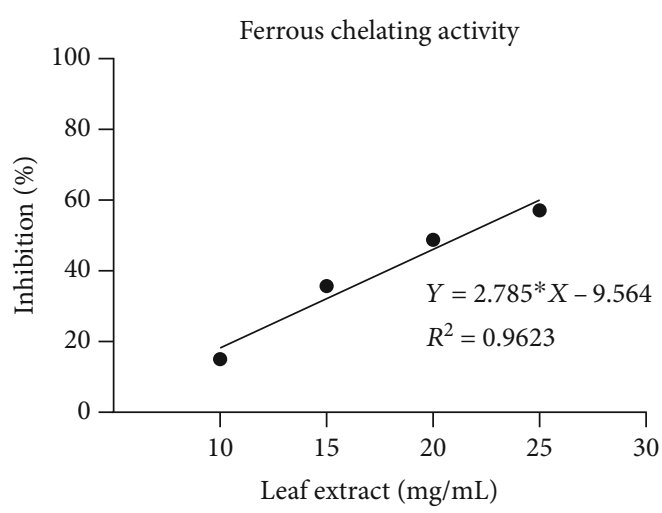

(c)

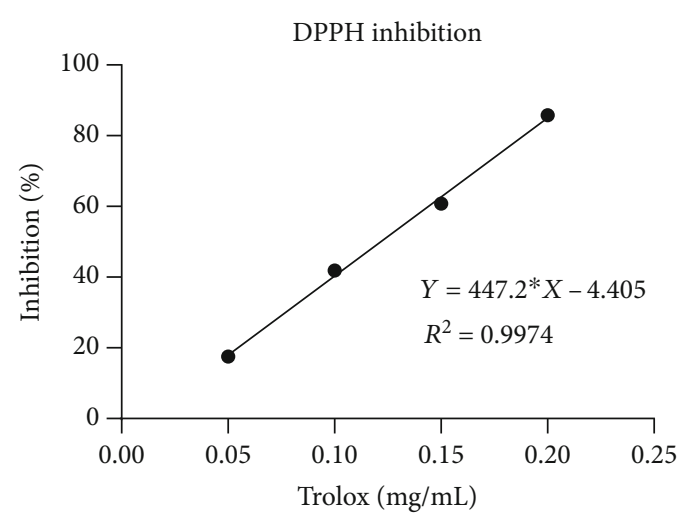

(b)

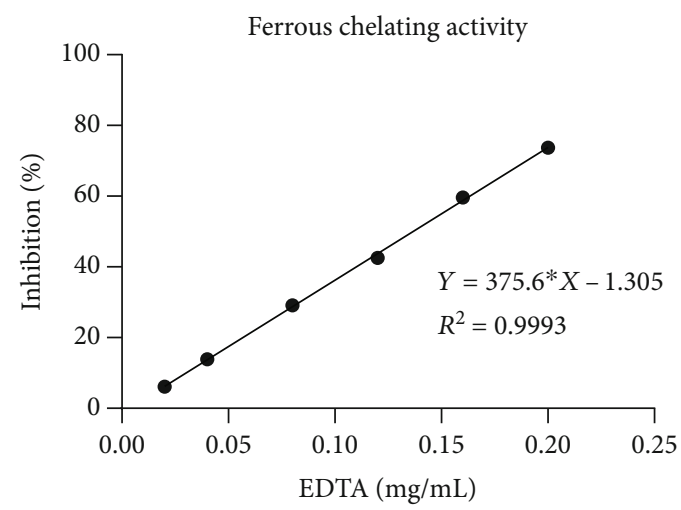

(d)

Figure 1: The determination of the antioxidant activity of (a) the leaf extract and (b) Trolox. Graphs plotted for the concentration of substance in $\mathrm{mg} / \mathrm{mL}$ versus percentage of the inhibition of DPPH. The determination of ferrous chelating activity of (c) the leaf extract and (d) EDTA. Graphs plotted for the concentration of substance in $\mathrm{mg} / \mathrm{mL}$ versus percentage of ferrous ion chelating effect.

3.2. Antioxidant and Ferrous Chelating Activities. The antioxidant property of Coccinia leaf extract was determined by $\mathrm{DPPH}$ scavenging assay compared to a standard, vitamin E derivative (Trolox). The leaf extract exhibited DPPH radical scavenging effect in a dose-dependent manner. The $\mathrm{IC}_{50}$ value of the leaf extract was $4.85 \mathrm{mg} / \mathrm{mL}$ or equaled to $98.96 \mu \mathrm{mol}$ Trolox equivalents per gram of extract (Figures 1(a) and 1(b)). The ability of DPPH radical scavenging indicated its ability to donate protons to DPPH and subsequently neutralize free radicals. Along with the generation of ROS during inflammation, iron is part of an interplay involving the generation of hydroxyl radicals and superoxide anions from iron redox cycling reaction (Fenton and HaberWeiss reaction) $[28,29]$. We showed that the leaf extract possessed an iron chelating property. Relative to the chelating agent, EDTA, Coccinia leaf extract had a ferrous ion chelating property with an $\mathrm{IC}_{50}$ value of $21.39 \mathrm{mg} / \mathrm{mL}$ or equaled to $22.39 \mu \mathrm{mol}$ EDTA equivalent per gram of extract (Figures 1(c) and 1(d)), suggesting that the leaf extract may lower the metal-induced radical formation and subsequently prevent the cellular oxidative damage in the prolonged inflammation.

3.3. Protective Effect of Coccinia Leaf Extract on Hydrogen Peroxide-Induced Oxidative Injury. In this study, hydrogen peroxide, $\mathrm{H}_{2} \mathrm{O}_{2}$, was used to induce cell death. Human fibro- blasts and keratinocytes were used to determine the sublethal dose of $\mathrm{H}_{2} \mathrm{O}_{2}$ (Figure 2(a)). We found that human fibroblast was more sensitive to $\mathrm{H}_{2} \mathrm{O}_{2}$-induced cytotoxicity than human keratinocytes. The treatment of $1 \mathrm{mM} \mathrm{H}_{2} \mathrm{O}_{2}$ on fibroblast cells led to $50.5 \pm 2.45 \%$ viability, while keratinocyte exhibited $51.14 \pm 3.52 \%$ viability upon $2 \mathrm{mM} \mathrm{H}_{2} \mathrm{O}_{2}$ treatment. The treatment of Coccinia leaf extract showed negligible cytotoxicity and minimal cell proliferative capacity on both cell lines all over the range of the extract concentrations (Figure 2(b)). The selected sublethal hydrogen peroxide dose was used to treat each cell line, and the capability of the leaf extract to rescue the hydrogen peroxide-induced cytotoxicity was monitored. $\mathrm{H}_{2} \mathrm{O}_{2}$ treatment alone (negative control) was used to induce oxidative stress damage in the cell, while Coccinia leaf extract treatment alone (positive control) showed minimal cytotoxicity in the cell (Figures 2(c) and 2(d)). Upon the treatment of the extract, the cytotoxicity of $\mathrm{H}_{2} \mathrm{O}_{2}$ induced oxidative damage was recovered in a dosedependent manner in both cell lines. The treatment of $200 \mu \mathrm{g} / \mathrm{mL}$ of the extract could rescue the cytotoxicity more than $27 \%$ compared with negative control, and the recovery was found to have no significant difference from the positive control. Together, this suggested that Coccinia leaf extract could ameliorate the human fibroblast and keratinocyte oxidative stress induced by $\mathrm{H}_{2} \mathrm{O}_{2}$. Next, we further tested whether the protective effect of the leaf extract relates to the 


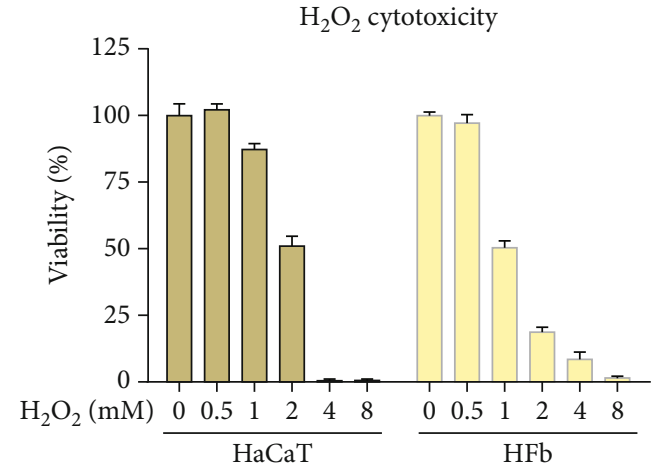

(a)

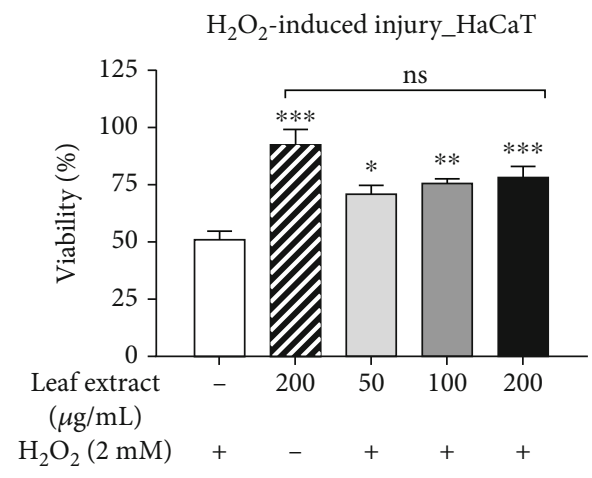

(c)

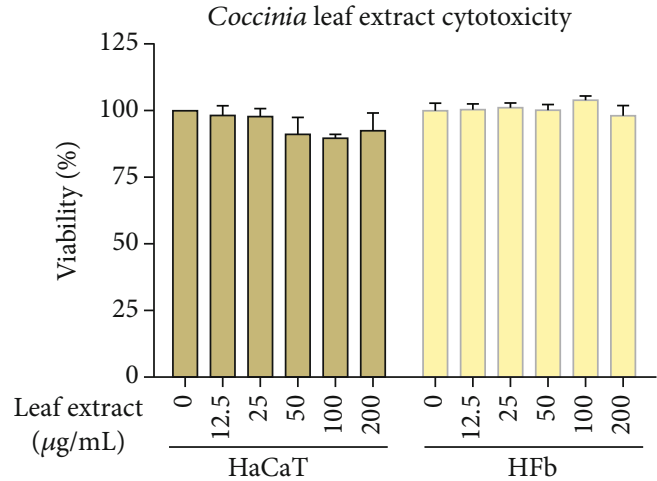

(b)

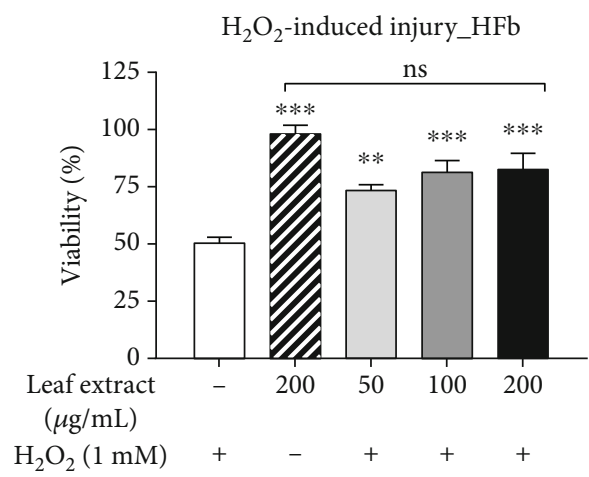

(d)

FIGURE 2: The graphs showed the viability of human keratinocyte, HaCaT, and human fibroblast, HFb, cell lines upon (a) hydrogen peroxide $\left(\mathrm{H}_{2} \mathrm{O}_{2}\right)$ treatment and (b) the leaf extract treatment. The capability of the leaf extracts to rescue the hydrogen peroxide-induced oxidative stress and cytotoxicity was employed in (c) HaCaT cell line and (d) HFb cell line. The data were analyzed with one-way ANOVA with Dunnett post hoc analysis, $n=6 .{ }^{*} P<0.05,{ }^{* *} P<0.01$, and ${ }^{* * *} P<0.001$ compared to hydrogen peroxide-treated condition $\left(+\mathrm{H}_{2} \mathrm{O}_{2}\right)$. Besides, the treatment of $200 \mu \mathrm{g} / \mathrm{mL}$ methanol leaf extract following hydrogen peroxide-induced oxidative stress and cytotoxicity was not significantly different (shown as "ns") compared with no hydrogen peroxide induction $\left(-\mathrm{H}_{2} \mathrm{O}_{2}\right)$.

intracellular ROS scavenging or else. We stained the cells with a cell-permeant dye, DCFH-DA, and determined the fluorescence intensity (Figures 3(a) and 3(b)). The amount of intracellular ROS was showed in relation with vehicle control treatment, $0.1 \%$ DMSO. Oxidative stress injury in human fibroblasts was induced by $1 \mathrm{mM} \mathrm{H}_{2} \mathrm{O}_{2}$, while oxidative stress injury in human keratinocytes was induced with $2 \mathrm{mM} \mathrm{H}_{2} \mathrm{O}_{2}$. The relative amount of fluorescence was analyzed in each cell line separately. Compared with vehicle control, the treatment of Coccinia leaf extract did not increase the intracellular ROS production in both cell lines, while $\mathrm{H}_{2} \mathrm{O}_{2}$ could induce ROS generation about two times more in human keratinocytes and five times more in human fibroblasts. This also correlated with the previous results showing that human fibroblast was more sensitive to oxidative stress injury than keratinocytes, even when they were treated with the lower $\mathrm{H}_{2} \mathrm{O}_{2}$ dose. We found that the treatment of the leaf extract reduced cellular ROS in both cell lines. The decrease of cellular ROS was observed even in the lowest test dose $(50 \mu \mathrm{g} / \mathrm{mL})$, and it continued to decrease ROS in a doserelated manner. Upon the supplement of the highest test dose $(200 \mu \mathrm{g} / \mathrm{mL})$ of the extract onto $\mathrm{H}_{2} \mathrm{O}_{2}$-induced ROS generation, the amount of cellular ROS was not significantly differ- ent from no oxidative stress damage (the condition of no $\mathrm{H}_{2} \mathrm{O}_{2}$ treatment), suggesting that the leaf extract could scavenge the intracellular ROS in both cell lines, in which its protective effect might correspond with the cellular oxidative stress (Figures 3(a)-3(d)).

3.4. Coccinia Leaf Extract Induced Cell Migration Revealed by Scratch Wound Healing Assay. In the attempt to evaluate the wound healing capacity, the scratching on fibroblasts and keratinocytes was employed to determine the effect of Coccinia leaf extract. The migration property of the extract was compared with a commercialized wound care drug: allantoin. The coverage area of the scratch was calculated and expressed as the percentage relative to time zero (accounted as 100\% scratching area). The scratching area of untreated human fibroblast and human keratinocyte monolayer is shown in Figures $3(\mathrm{e})$ and $3(\mathrm{f})$, respectively. We demonstrated that the leaf extract induced human fibroblast and keratinocyte cell migration in a dose-related capability. The lowest test dose, $50 \mu \mathrm{g} / \mathrm{ml}$ extract, was observed to reduce the scratched area up to $13 \%$ in keratinocytes and $17 \%$ in fibroblasts compared to vehicle control treatment $(0.1 \%$ DMSO), whereas the maximum dose of $200 \mu \mathrm{g} / \mathrm{mL}$ leaf extract enhanced the 


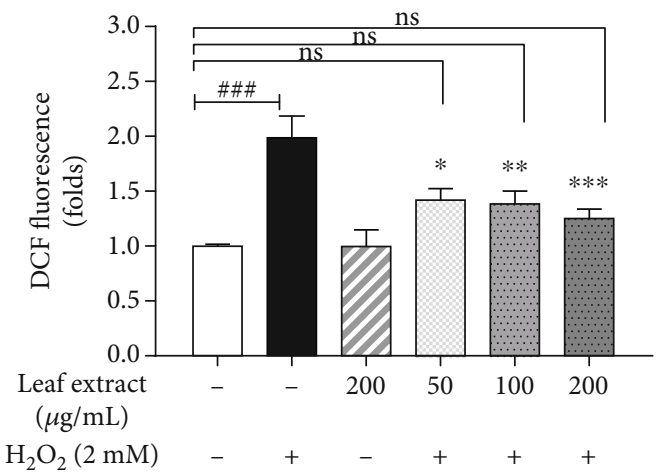

(a)
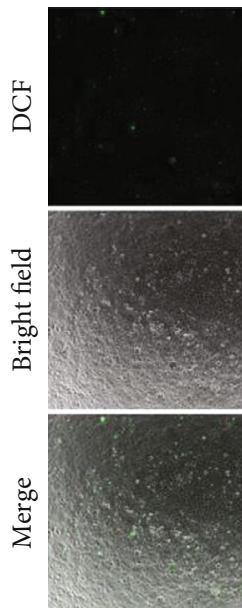

Control
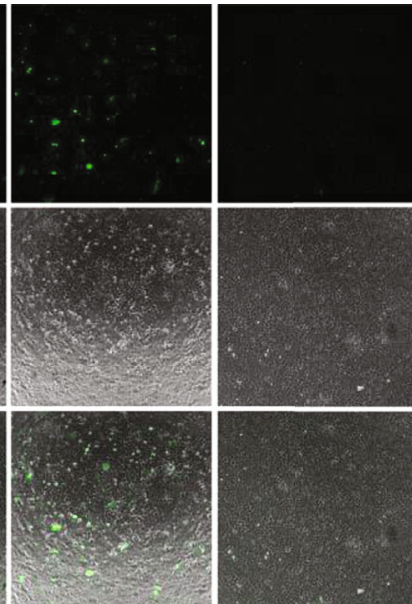

$\mathrm{H}_{2} \mathrm{O}_{2}$

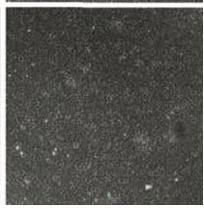

$\mathrm{H}_{2} \mathrm{O}_{2}+$ $\mathrm{MeOH}$ extract

(c)

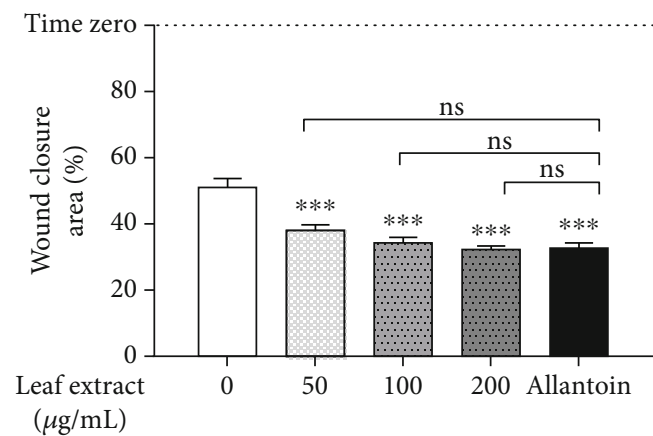

(e)

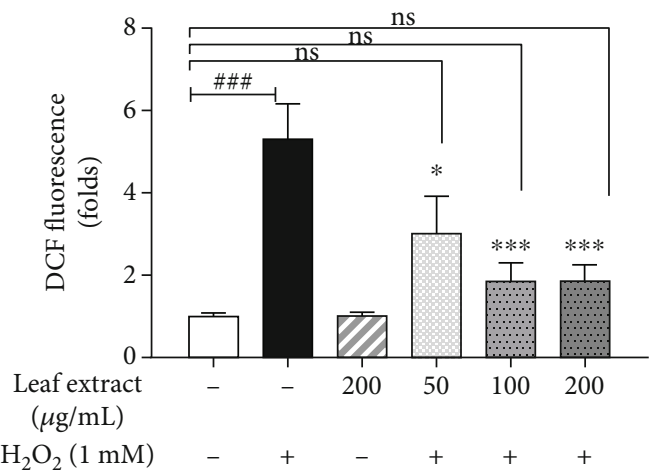

(b)

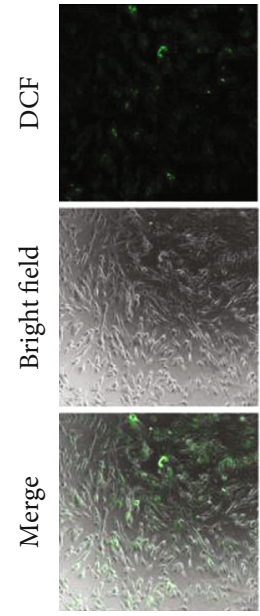

Control
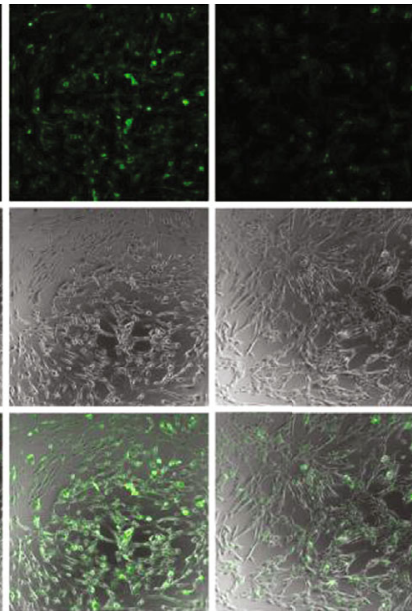

$\mathrm{H}_{2} \mathrm{O}_{2}$

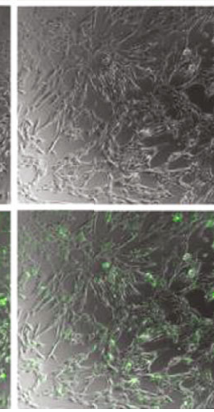

$\mathrm{H}_{2} \mathrm{O}_{2}+$

$\mathrm{MeOH}$ extract

(d)

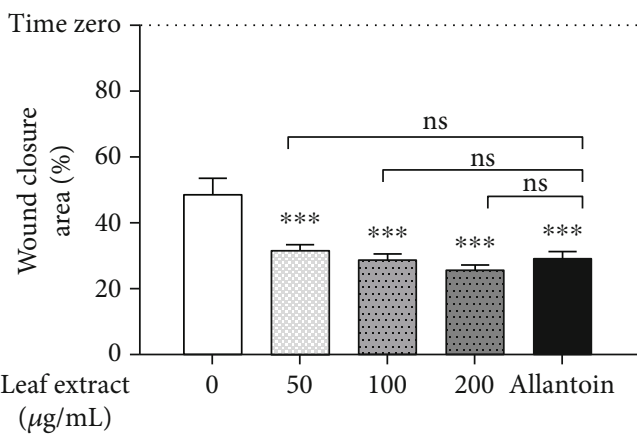

(f)

FIGURE 3: The effect of Coccinia leaf extract on the reduction of reactive oxygen species upon hydrogen peroxide-induced oxidative stress and cytotoxicity was employed by DCF fluorescence staining in ( $a, c) \mathrm{HaCaT}$ cell line and (b, d) HFb cell line. The fluorescence intensities were expressed in fold changes compared to vehicle control $\left(-\mathrm{H}_{2} \mathrm{O}_{2}\right.$-leaf extract). The effect of leaf extract on the migration of (e) HaCaT cells and (f) $\mathrm{HFb}$ cells was shown as a wound closure area or the remaining area uncovered by the cells. The scratch-wound closure was monitored fifteen hours later. The scratch area at time zero was set to $100 \%$. The data were analyzed with one-way ANOVA with Dunnett post hoc analysis, $n=6$. The methanol leaf extract treatments $\left(+\mathrm{H}_{2} \mathrm{O}_{2}+\right.$ leaf extract $)$ showed as ${ }^{*} P<0.05,{ }^{* *} P<0.01$, and ${ }^{* * *} P<0.001$ compared with hydrogen peroxide treatment $\left(+\mathrm{H}_{2} \mathrm{O}_{2}\right)$. Besides, the methanol leaf extract treatment at all range of concentrations $\left(+\mathrm{H}_{2} \mathrm{O}_{2}+\right.$ leaf extract) showed no significant difference ("ns") from vehicle control (- $\mathrm{H}_{2} \mathrm{O}_{2}$-leaf extract).

cell migration, which reduced the scratched area by about $19 \%$ in keratinocytes and $23 \%$ in fibroblasts. We found that the potential effect of the leaf extract on wound healing assay was similar to allantoin at all ranges of test doses. This effect was observed in both cell lines. Together, this indicated that the Coccinia leaf extract efficiently enhanced the migratory capacity of cells, which accelerated the wound healing process. 


\section{Discussion}

Upon tissue damage, several cascades respond to the injury and alleviate the suffering. One of those cascades is the inflammatory process, which is aimed at eliminating the invading pathogen, getting rid of tissue debris, and secreting secondary messengers to initiate the downstream pathways. In the normal wound healing, the ROS such as superoxide radicals, hydroxyl radical, and hydrogen peroxide act as the secondary messengers to regulate downstream pathways such as tissue inflammation and proliferation [30]. The generations of reactive oxygen species and reactive nitrogen species are normal defense mechanisms following the inflammatory process. Due to the short half-life of superoxide anions, they are catalyzed by superoxide dismutase to hydrogen peroxide, a relatively stable compound. Although hydrogen peroxide is safer than other oxidants, its accumulation during the prolonged stimulation of the inflammatory process can further regenerate hydroxyl radicals via the Fenton reaction. Iron is the abundant transition metal in our body. It is involved in the redox cycling pathway in the cell to generate hydroxyl radicals from hydrogen peroxide. A previous study showed that the imbalance of iron homeostasis has been described in several chronic inflammatory diseases [29]. Under the pathological process, the dysregulated, incomplete, or overactive inflammation results in abnormal wound healing such as scars, keloids, and chronic wounds. The balance between proinflammation and antiinflammation needs to be well regulated to control the damage and minimize tissue injuries. Otherwise, the prolonged inflammation may result in an excessive free radical which further damages tissue. Therefore, the constriction of the inflammation stage was targeted to manage the severity of the injury [31-33].

Severe nonhealing wounds could lead to infection and amputation. The estimated prevalence of global chronic wounds was 2.21 cases per 1,000 population [34]. The cost of wound management was estimated to be around 28 to 96 billion US dollars annually [35]. The treatment of a wound appeared to be expensive, especially in chronic, nonhealing wounds which sustain the cost for a longer period. Due to the high economic burden, several countries increase the use of phytomedicine in chronic wounds as they have an affordable price. Although natural products possibly have higher safety concerns than chemical-based therapy, potential property, activity, and validation by scientific methods need to be determined. Previously, natural products such as honey, chamomile, rosemary, and turmeric were used as therapeutic agents for reducing inflammation in wound management [31, 36-38]. For instance, chamomile has been used as a wound care product under the trade name "Kamillosan." It accelerates tissue epithelization which results in wound drying and also acts as an antioxidant and antiinflammatory agent $[39,40]$. The other well-known natural product for wound care is honey. Its medicinal properties are related to the effects of antioxidants and antiinflammation that restricted the oxidative injury and advanced the wound healing process $[41,42]$. The antioxidant properties of natural products from plants were related to the enrichment of polyphenol constitutes [43-48]. Due to the chemical structure of phenolic compounds, it scavenges free radicals by transferring electrons and $\mathrm{H}$-atoms from their $\mathrm{OH}$-group(s) to the free radicals thereby exhibiting antioxidant property [49]. Besides scavenging free radicals, phenolic compounds also scavenge nonradical reactive species such as hydrogen peroxide by donating electrons and $\mathrm{H}$-atoms to hydrogen peroxide which can subsequently be converted to water molecules [27]. As a good electron and proton donor, the phenolic compound acts as a chelator of several transition metal ions such as zinc $\left(\mathrm{Zn}^{2+}\right)$, iron $\left(\mathrm{Fe}^{2+}\right)$, and copper $\left(\mathrm{Cu}^{2+}\right)$ which is beneficial for lowering metal-induced oxidative stress injury. Moreover, previous studies found that the polyphenolic compound reduced the activity of enzymes involved in ROS formation [50-52]. Polyphenols also temper the immune response by modulation of inflammatory cytokines [53]. Besides the antiinflammation and antioxidant properties of phenolic compounds, they have been found to enhance fibroblast migration which promotes the wound repairing process, although the mechanism of action has not been described yet [54].

Nowadays, the usage of plant-based medication is increasing. In this study, we were interested in the effect of Coccinia leaf extract on the modulation of oxidative stress damage and its related wound healing properties. In ancient times, this medicinal plant was used to reduce the swelling and itching from an insect bite. This suggested its ability to decrease the inflammatory process. Recent studies have revealed the metabolic profile of the Coccinia leaf extract and its ability to enhance wound healing in vivo [21,22]. However, it has not been tested in the cell culture model yet, especially its antioxidant properties and its role on cell migratory effect. In this present study, we showed that the leaf extract possessed considerable polyphenolic and flavonoid contents. The leaf extract could rescue cell survival in hydrogen peroxide-induced oxidative stress damage. Following the tests of antioxidant assays, the leaf extract was capable to decrease free radicals and chelate the ferrous ions. Fibroblasts were very sensitive to the hydrogen peroxide-induced oxidative damage than keratinocytes. The cytotoxicity of fibroblast may result in the lack of extracellular matrix deposition, hampering wound contraction, and delaying tissue remodeling process. Here, we have first demonstrated that Coccinia leaf extract could reduce the oxidative stress damage in both human fibroblast and keratinocyte cell lines.

During the wound healing process, fibroblast and keratinocytes are attracted to the site of injury following the chemotactic secretion from inflammatory cells and are responsible for granulation and reepithelization of tissue. They initiate cell proliferation and tissue formation that occur in the late phase of inflammation till the remodeling phase of wound healing $[1,55]$. Keratinocytes have released numbers of proteins to reconstitute the damaged epidermis and basement membrane, while fibroblasts undergo proliferation and modify their interaction with the extracellular matrix to recreate healthy granulation tissue $[1,55]$. In this study, the wound healing property of the leaf extract was determined by scratch wound healing assay [56]. This reliable method has been described by Lampugnani in 1999 
and was used in several previous studies in comparison to in vivo study models [57-60]. Upon the scratch wound assay, we showed that the Coccinia leaf extract could reduce the scratched area in both keratinocytes and fibroblast cells. This appearance could be either by the induction of cell migration to cover the scratched area or by the increase of cell proliferation, but we found that the Coccinia leaf extract did not increase the cell number at all test concentrations. Thus, we believed that the wound healing property of the Coccinia leaf extract was related to the modulation of cell migration. Interestingly, the leaf extract could induce the cell migration to a similar level as commercializing wound care product allantoin. The mechanisms of action of allantoin to promote wound healing were related to the modulation of an inflammatory response and the induction of fibroblast proliferation and reepithelization [61-63]. Our finding demonstrated that the potential effect of the Coccinia leaf extract on wound healing was related to its antioxidant properties and the induction of cell migration.

\section{Conclusion}

The accumulation of hydrogen peroxide is present in chronic wound healing as well as several chronic inflammatory diseases such as atherosclerosis, diabetes, and systemic inflammatory response syndrome. In this study, we showed that the Coccinia leaf extract could alleviate the cytotoxicity from hydrogen peroxide exposure, in vitro. It also had beneficial effects on wound healing process by promoting the migration of fibroblasts and keratinocytes. Due to the easiness and low cost of Coccinia maintenance, this could accommodate the usage of this medicinal plant as a natural antioxidant, antiinflammatory agent, and wound care product. However, further study is needed to investigate the other wound healing mechanism of the leaf extract.

\section{Data Availability}

All datasets generated during the study are included in the article.

\section{Conflicts of Interest}

The authors declare that they have no conflicts of interest.

\section{Authors' Contributions}

P.N., C.N., and Y.J. were responsible for conceptualization. P.N., P.R., and Y.J. contributed in formal analysis. P.R., K.M., and Y.J. contributed in investigation. P.N. and A.A. contributed in writing, review, and editing. K.M. and Y.J. contributed in visualization. Y.J. and P.R. were responsible for supervision. P.N. and C.N. were responsible for project administration. Y.J. was responsible for funding acquisition.

\section{Acknowledgments}

The authors would like to thank Ruttachuk Rungsiwiwut, DVM, Ph.D., from the Department of Anatomy, Faculty of Medicine, Srinakharinwirot University, Thailand, for his helpful advice in this study. This research project was supported by CIF and CNI Grant, Faculty of Science, Mahidol University, and the research grant of the Faculty of Medicine, Srinakharinwirot University, Thailand.

\section{References}

[1] A. Sharma, L. R. Zakka, and M. C. Mihm, "Anatomy of the human skin and wound healing," in in Bioengineering in Wound Healing, pp. 27-57, World Scientific, 2016.

[2] T. J. Koh and L. A. DiPietro, "Inflammation and wound healing: the role of the macrophage," Expert Reviews in Molecular Medicine, vol. 13, article e23, 2011.

[3] P. Bainbridge, "Wound healing and the role of fibroblasts," Journal of Wound Care, vol. 22, no. 8, pp. 407-412, 2013.

[4] C. Dunnill, T. Patton, J. Brennan et al., "Reactive oxygen species (ROS) and wound healing: the functional role of ROS and emerging ROS-modulating technologies for augmentation of the healing process," International Wound Journal, vol. 14, no. 1, pp. 89-96, 2017.

[5] C. N. Paiva and M. T. Bozza, "Are reactive oxygen species always detrimental to pathogens?," Antioxidants \& Redox Signaling, vol. 20, no. 6, pp. 1000-1037, 2014.

[6] I. Pastar, O. Stojadinovic, and M. Tomic-Canic, "Role of keratinocytes in healing of chronic wounds," Surgical Technology International, vol. 17, pp. 105-112, 2008.

[7] S. Werner, T. Krieg, and H. Smola, "Keratinocyte-fibroblast interactions in wound healing," Journal of Investigative Dermatology, vol. 127, no. 5, pp. 998-1008, 2007.

[8] R. Moseley, J. E. Stewart, P. Stephens, R. J. Waddington, and D. W. Thomas, "Extracellular matrix metabolites as potential biomarkers of disease activity in wound fluid: lessons learned from other inflammatory diseases?," British Journal of Dermatology, vol. 150, no. 3, pp. 401-413, 2004.

[9] I. B. Wall, R. Moseley, D. M. Baird et al., "Fibroblast Dysfunction Is a Key Factor in the Non-Healing of Chronic Venous Leg Ulcers," Journal of Investigative Dermatology, vol. 128, no. 10, pp. 2526-2540, 2008.

[10] D. Lim, "Coccinia grandis," in Edible Medicinal And NonMedicinal Plants, pp. 191-200, Springer, 2012.

[11] P. Sakharkar and B. Chauhan, "Antibacterial, antioxidant and cell proliferative properties of Coccinia grandis fruits," Avicenna journal of phytomedicine, vol. 7, no. 4, pp. 295-307, 2017.

[12] D. Kondhare and H. Lade, "Phytochemical profile, aldose reductase inhibitory, and antioxidant activities of Indian traditional medicinal Coccinia grandis (L.) fruit extract," 3 Biotech, vol. 7, no. 6, 2017.

[13] S. S. Pekamwar, T. M. Kalyankar, and S. S. Kokate, "Pharmacological activities of Coccinia grandis: review," Journal of Applied Pharmaceutical Science, vol. 3, pp. 114-119, 2013.

[14] K. Ramachandran and B. Subramaniam, "Scarlet gourd Coccinia grandis little-known tropical drug plant," Economic Botany, vol. 37, no. 4, pp. 380-383, 1983.

[15] E. Wasantwisut and T. Viriyapanich, "Ivy gourd (Coccinia grandis Voigt, Coccinia cordifolia, Coccinia indica) in human nutrition and traditional applications," World Review of Nutrition and Dietetics, vol. 91, pp. 60-66, 2003.

[16] I. G. Doka, S. El Tigani, and S. Yagi, "Amino acid content, fatty acid profile and radical scavenging capacities of Coccinia 
grandis (L.) Voigt. fruits," Advance Journal of Food Science and Technology, vol. 6, pp. 1307-1312, 2014.

[17] K. Jayatilaka, A. Attanayake, and M. Arawwawala, "Chemical standardization of leaf extract of Coccinia grandis (L.) Voigt (Cucurbitaceae) of Sri Lankan origin," Journal of Pharmacognosy and Phytochemistry, vol. 119, pp. 119-123, 2016.

[18] A. Attanayake and K. Jayatilaka, "Anti-diabetic potential of ivy gourd (Coccinia grandis, family: Cucurbitaceae) grown in Sri Lanka: a review Dr. AP Attanayake, KAPW Jayatilaka and LKB Mudduwa," Journal of Pharmacognosy and Phytochemistry, vol. 286, pp. 286-289, 2016.

[19] M. Umamaheswari and T. K. Chatterjee, "In vitro antioxidant activities of the fractions of Coccinia grandis L. leaf extract," African Journal of Traditional, Complementary and Alternative Medicines, vol. 5, no. 1, pp. 61-73, 2007.

[20] R. Bunkrongcheap, N. Hutadilok-Towatana, K. Noipha, C. Wattanapiromsakul, M. Inafuku, and H. Oku, "Ivy gourd (Coccinia grandis L. Voigt) root suppresses adipocyte differentiation in 3T3-L1 cells," Lipids in Health and Disease, vol. 13, no. 1, p. $88,2014$.

[21] B. Deepti, K. Sasidhar, G. Sadhana, and S. Thaakur, "Wound healing activity of chloroform extract of Coccinia grandis on excision, incision \& dead space wound model in rats," International Journal of Research in Pharmaceutical Sciences, vol. 3, pp. 470-475, 2012.

[22] S. A. Al-Madhagy, N. M. Mostafa, F. S. Youssef, G. E. A. Awad, O. A. Eldahshan, and A. N. B. Singab, "Metabolic profiling of a polyphenolic-rich fraction of Coccinia grandis leaves using LC-ESI-MS/MS and in vivo validation of its antimicrobial and wound healing activities," Food \& Function, vol. 10, no. 10, pp. 6267-6275, 2019.

[23] K. Slinkard and V. L. Singleton, "Total phenol analysis: automation and comparison with manual methods," American Journal of Enology and Viticulture, vol. 28, no. 1, pp. 49-55, 1977.

[24] C.-C. Chang, M.-H. Yang, H.-M. Wen, and J.-C. Chern, "Estimation of total flavonoid content in propolis by two complementary colorimetric methods," Journal of Food and Drug Analysis, vol. 10, pp. 178-182, 2002.

[25] D. Huang, B. Ou, and R. L. Prior, "The chemistry behind antioxidant capacity assays," Journal of Agricultural and Food Chemistry, vol. 53, no. 6, pp. 1841-1856, 2005.

[26] K. E. Heim, A. R. Tagliaferro, and D. J. Bobilya, "Flavonoid antioxidants: chemistry, metabolism and structure-activity relationships," The Journal of Nutritional Biochemistry, vol. 13, no. 10, pp. 572-584, 2002.

[27] C. Papuc, G. V. Goran, C. N. Predescu, V. Nicorescu, and G. Stefan, "Plant polyphenols as antioxidant and antibacterial agents for shelf-life extension of meat and meat products: classification, structures, sources, and action mechanisms," Comprehensive Reviews in Food Science and Food Safety, vol. 16, no. 6, pp. 1243-1268, 2017.

[28] M. Wessling-Resnick, "Iron homeostasis and the inflammatory response," Annual Review of Nutrition, vol. 30, no. 1, pp. 105-122, 2010.

[29] C. Lehmann, S. Islam, S. Jarosch et al., "The utility of iron chelators in the management of inflammatory disorders," Mediators of Inflammation, vol. 2015, Article ID 516740, 12 pages, 2015.

[30] M. Schäfer and S. Werner, "Oxidative stress in normal and impaired wound repair," Pharmacological Research, vol. 58, no. 2, pp. 165-171, 2008.
[31] S. D. Fitzmaurice, R. K. Sivamani, and R. R. Isseroff, "Antioxidant therapies for wound healing: a clinical guide to currently commercially available products," Skin Pharmacology and Physiology, vol. 24, no. 3, pp. 113-126, 2011.

[32] V.-L. Nguyen, C. T. Truong, B. C. Q. Nguyen et al., "Antiinflammatory and wound healing activities of calophyllolide isolated from Calophyllum inophyllum Linn," PLoS One, vol. 12, no. 10, article e0185674, 2017.

[33] S. K. Dev, P. K. Choudhury, R. Srivastava, and M. Sharma, "Antimicrobial, anti-inflammatory and wound healing activity of polyherbal formulation," Biomedicine \& Pharmacotherapy, vol. 111, pp. 555-567, 2019.

[34] L. Martinengo, M. Olsson, R. Bajpai et al., "Prevalence of chronic wounds in the general population: systematic review and meta-analysis of observational studies," Annals of Epidemiology, vol. 29, pp. 8-15, 2019.

[35] S. R. Nussbaum, M. J. Carter, C. E. Fife et al., "An economic evaluation of the impact, cost, and Medicare policy implications of chronic nonhealing wounds," Value in Health, vol. 21, no. 1, pp. 27-32, 2018.

[36] A. Simon, K. Traynor, K. Santos, G. Blaser, U. Bode, and P. Molan, "Medical honey for wound care-still the "latest resort'?," Evidence-Based Complementary and Alternative Medicine, vol. 6, no. 2, 173 pages, 2009.

[37] N. Ibrahim, S. Wong, I. Mohamed et al., "Wound healing properties of selected natural products," International Journal of Environmental Research and Public Health, vol. 15, no. 11, p. 2360, 2018.

[38] T. Maver, U. Maver, K. Stana Kleinschek, D. M. Smrke, and S. Kreft, "A review of herbal medicines in wound healing," International Journal of Dermatology, vol. 54, no. 7, pp. 740-751, 2015.

[39] O. Singh, Z. Khanam, N. Misra, and M. K. Srivastava, "Chamomile (Matricaria chamomilla L.): an overview," Pharmacognosy Reviews, vol. 5, no. 9, pp. 82-95, 2011.

[40] S. Petronilho, M. Maraschin, M. A. Coimbra, and S. M. Rocha, "In vitro and in vivo studies of natural products: a challenge for their valuation. The case study of chamomile (Matricaria recutita L.)," Industrial Crops and Products, vol. 40, pp. 1-12, 2012.

[41] R. Yaghoobi, A. Kazerouni, and O. Kazerouni, "Evidence for clinical use of honey in wound healing as an anti-bacterial, anti-inflammatory anti-oxidant and anti-viral agent: a review," Jundishapur Journal of Natural Pharmaceutical Products, vol. 8, no. 3, pp. 100-104, 2013.

[42] N. Al-Waili, K. Salom, and A. A. Al-Ghamdi, "Honey for wound healing, ulcers, and burns; data supporting its use in clinical practice," TheScientificWorldJOURNAL, vol. 11, pp. 766-787, 2011.

[43] T. P. Kondratyuk and J. M. Pezzuto, "Natural product polyphenols of relevance to human health," Archives of Physiology and Biochemistry, vol. 42, no. s1, pp. 46-63, 2004.

[44] R. Tsao, "Chemistry and biochemistry of dietary polyphenols," Nutrients, vol. 2, no. 12, pp. 1231-1246, 2010.

[45] A. B. Enogieru, W. Haylett, D. C. Hiss, S. Bardien, and O. E. Ekpo, "Rutin as a potent antioxidant: implications for neurodegenerative disorders," Oxidative Medicine and Cellular Longevity, vol. 2018, Article ID 6241017, 17 pages, 2018.

[46] J. Bae, N. Kim, Y. Shin, S.-Y. Kim, and Y.-J. Kim, "Activity of catechins and their applications," Biomedical Dermatology, vol. 4 , no. 1 , p. $8,2020$. 
[47] J. Bernatoniene and D. Kopustinskiene, "The role of catechins in cellular responses to oxidative stress," Molecules, vol. 23, no. 4 , p. $965,2018$.

[48] K. G. Samuel, J. Wang, H. Y. Yue et al., "Effects of dietary gallic acid supplementation on performance, antioxidant status, and jejunum intestinal morphology in broiler chicks," Poultry Science, vol. 96, no. 8, pp. 2768-2775, 2017.

[49] F. Di Meo, E. Anouar, P. Podloucká, G. Fabre, and P. Trouillas, "Understanding antioxidant properties of natural compounds at the atomic scale," Journal of the Serbian Society for Computational Mechanics, vol. 7, pp. 58-70, 2014.

[50] B. S. Cheon, Y. H. Kim, K. S. Son, H. W. Chang, S. S. Kang, and H. P. Kim, "Effects of prenylated flavonoids and biflavonoids on lipopolysaccharide-induced nitric oxide production from the mouse macrophage cell line RAW 264.7," Planta Medica, vol. 66, no. 7, pp. 596-600, 2000.

[51] J. Hong, T. J. Smith, C. T. Ho, D. A. August, and C. S. Yang, "Effects of purified green and black tea polyphenols on cyclooxygenase- and lipoxygenase-dependent metabolism of arachidonic acid in human colon mucosa and colon tumor tissues," Biochemical Pharmacology, vol. 62, no. 9, pp. 1175-1183, 2001.

[52] R. J. Nijveldt, E. van Nood, D. E. C. van Hoorn, P. G. Boelens, K. van Norren, and P. A. M. van Leeuwen, "Flavonoids: a review of probable mechanisms of action and potential applications," The American Journal of Clinical Nutrition, vol. 74, no. 4, pp. 418-425, 2001.

[53] N. Yahfoufi, N. Alsadi, M. Jambi, and C. Matar, "The immunomodulatory and anti-inflammatory role of polyphenols," Nutrients, vol. 10, no. 11, p. 1618, 2018.

[54] Y. Ponnusamy, N. J. Y. Chear, S. Ramanathan, and C. S. Lai, "Polyphenols rich fraction of Dicranopteris linearis promotes fibroblast cell migration and proliferation in vitro," Journal of Ethnopharmacology, vol. 168, pp. 305-314, 2015.

[55] P. Martin, "Wound healing-aiming for perfect skin regeneration," Science, vol. 276, no. 5309, pp. 75-81, 1997.

[56] M. G. Lampugnani, "Cell migration into a wounded area in vitro," Methods in Molecular Biology, vol. 96, pp. 177-182, 1999.

[57] Y. Chen, "Scratch wound healing assay," Bio-Protocol, vol. 2, no. 5, article e100, 2012.

[58] M. Carretero, M. J. Escámez, M. García et al., "In vitro and in vivo wound healing-promoting activities of human cathelicidin LL-37," The Journal of Investigative Dermatology, vol. 128, no. 1, pp. 223-236, 2008.

[59] A. D’Agostino, A. Stellavato, T. Busico et al., "In vitro analysis of the effects on wound healing of high- and low-molecular weight chains of hyaluronan and their hybrid H-HA/L-HA complexes," BMC Cell Biology, vol. 16, no. 1, p. 19, 2015.

[60] T.-J. Ho, S. J. Jiang, G. H. Lin et al., "The in vitro and in vivo wound healing properties of the Chinese herbal medicine "Jinchuang ointment"," Evidence-based Complementary and Alternative Medicine, vol. 2016, 11 pages, 2016.

[61] L. U. Araújo, A. Grabe-Guimarães, V. C. F. Mosqueira, C. M. Carneiro, and N. M. Silva-Barcellos, "Profile of wound healing process induced by allantoin," Acta Cirúrgica Brasileira, vol. 25, no. 5, pp. 460-461, 2010.
[62] J. Frikeche, C. Couteau, C. Roussakis, and L. J. M. Coiffard, "Research on the immunosuppressive activity of ingredients contained in sunscreens," Archives of Dermatological Research, vol. 307, no. 3, pp. 211-218, 2015.

[63] M. P. Jorge, C. Madjarof, A. L. T. G. Ruiz et al., "Evaluation of wound healing properties of Arrabidaea chica Verlot extract," Journal of Ethnopharmacology, vol. 118, no. 3, pp. 361-366, 2008. 